\title{
Mamdani fuzzy rule-based models for psychological research
}

\author{
Deepak Chandra Pandey ${ }^{1} \cdot$ Govind Singh Kushwaha ${ }^{2} \cdot$ Sanjay Kumar ${ }^{1}$
}

Received: 14 October 2019 / Accepted: 8 April 2020 / Published online: 16 April 2020

(c) Springer Nature Switzerland AG 2020

\begin{abstract}
The biasness of the participants in psychological research cannot be ignored during answering various psychological questioners or inventory. Hence, the prediction of psychological parameters can be deemed an ambiguous endeavor and fuzzy modeling provides a mean to account for this ambiguity and uncertainty. In the present study, two fuzzy rulebased models that use single input and generate single output are developed to convert the raw scores of neuroticism and extraversion to standard scores. Maudsley personality inventory (MPI) and Sinha's comprehensive anxiety test (SCAT) were used to collect raw data of neuroticism, extraversion and anxiety from participants. Using the standard scores for neuroticism and extroversion, third fuzzy rule-based model is also developed to predict the anxiety level of the participants. Each model is a collection of fuzzy rules that express the relationship of each input to the output. The performance of all developed models is tested by estimating mean absolute percentage error (MAPE) and paired two-tailed $t$ test.
\end{abstract}

Keywords Fuzzy model $\cdot$ Extraversion $\cdot$ Neuroticism $\cdot$ Anxiety $\cdot$ Uncertainty

\section{Introduction}

Human behavior depends on number of psychological parameters, and extraversion, neuroticism, anxiety are few of them. Extraversion represents tendency to be sociable, assertive, active and directive. Neuroticism represents a tendency to exhibit poor emotional adjustment and experiences negative effect such as fear, anxiety, and impulsivity $[12,20]$. Studies show that extraversion is associated with happiness, whereas neuroticism is associated with unhappiness [4, 22]. Many studies have established an association between anxiety and neuroticism [2]. Anxiety represents a 'state of arousal' caused by threat to wellbeing [28]. It means a condition of tension, uneasiness, threat and readiness which involves an entire organism to act and respond. 'Threat' means anticipation of pain, danger or serious interference with goal seeking activities.
Simulation of human behavior as an interdisciplinary research field has attracted the keen interest of mathematician and psychologist. In recent years, it has been extensively studied and applied in psychological research [21]. Zadeh [33] gave the notion of fuzzy set to handle the uncertainty which is caused by imprecise information and vague data. The interest of psychologist in fuzzy logic has visibly been growing since mid-1980s $[1,11,25,26]$. Psychology is not only a field in which profound applications of fuzzy logic is anticipated, but is also very important for the development of fuzzy set theory itself [34]. Fuzzy logic allows researchers to handle the imprecision and vague inherence of input data in depth and develop more reliable model for computing input-output relations [17]. Many researchers $[6,7,13,16,18,19,29,30]$ proposed integration of fuzzy logic in psychological research for more logical outcomes. Recently Devi [5] and Laifa [15]

Govind Singh Kushwaha, drgovindsingh@hotmail.com; Deepak Chandra Pandey, deechp2006@gmail.com; Sanjay Kumar, skruhela@hotmail.com | 1'Department of Mathematics, Statistics and Computer Science, College of Basic Sciences and Humanities, G.B Pant University of Agriculture and Technology, Pantnagar 263145, India. ${ }^{2}$ Department of Social Sciences and Humanities, College of Basic Sciences and Humanities, G.B Pant University of Agriculture and Technology, Pantnagar 263145, India. 
integrated fuzzy set theory with neural network to develop intelligent models for psychological research.

In the area of simulation of human behavior, a common modeling approach is to develop empirical models from questionnaire $[9,21,24]$. However, databases related to the parameters that control human behavior are too imprecise and vague to be described by random measures. Hence, prediction of personality can be deemed as an ambiguous endeavor and fuzzy modeling provides a mean to account for this ambiguity and uncertainty $[8,25,26]$.

The uncertainty which is caused by imprecision and vague data is hard to deal using probability theory as many researchers $[3,10,11,13,31]$ promoted fuzzy modeling for the simulation of human behavior and fuzzy logic was used to process qualitative variables to represent personality to give systematic knowledge of human personality. Earlier few models of personality traits were developed that included extroversion, neuroticism, sensitive, realistic, selfish, hostile and fuzzy logic based adaptive model of emotions $[8,23,27]$.

The purpose of this study is to develop Mamdani fuzzy rule-based models to get standard scores of neuroticism and extroversion from respective raw scores. Here, the scores of neuroticism and extraversion that are obtained using questionnaire are referred as raw scores. These standard scores of neuroticism and extraversion are used as inputs in another Mamdani fuzzy rule-based model that predicts the anxiety of the participants. Even though fuzzy modeling methods have been studied for decades, very few studies based on fuzzy modeling are found in the
Fig. 1 Flow-chart of overall process of development and analysis of the models

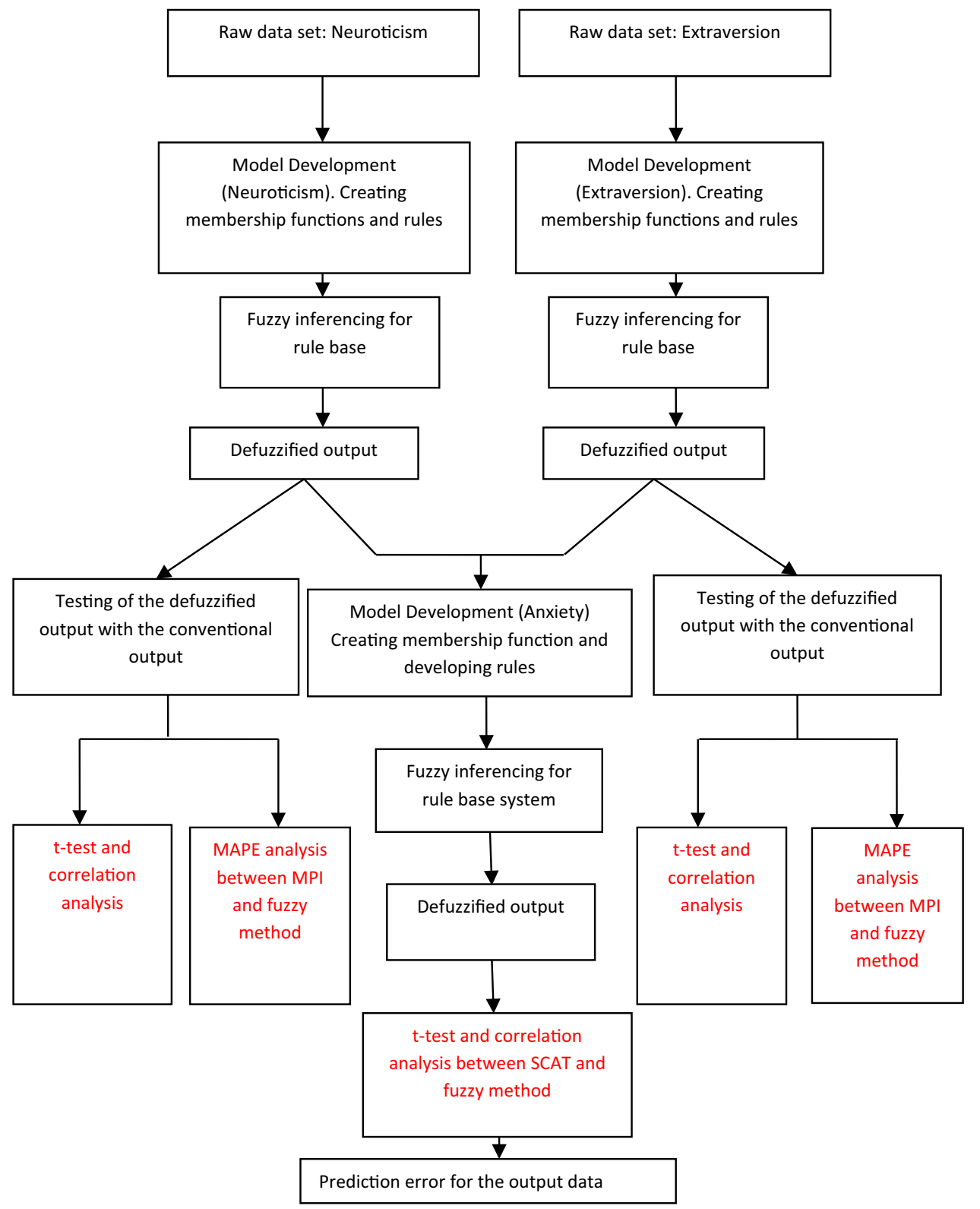


study of psychological parameters. Novelty of this paper is that it proposes a novel fuzzy rule-based model to convert raw scores to standard scores of neuroticism and extraversion. Enhanced standard scores of neuroticism and extraversion that are obtained using fuzzy models are used in another fuzzy model as input to enhance the accuracy in the prediction anxiety of the participants. The process begins with collection of raw data for neuroticism and extraversion using Maudsley personality inventory (MPI) [9] and Sinha's comprehensive anxiety test (SCAT) [24]. The whole process is illustrated in Fig. 1. The accuracy of the proposed models is tested in terms of mean absolute percentage error (MAPE). Paired two-tailed $t$ test and Pearson's correlation coefficients are used in this study to verify the performance of developed fuzzy rule-based models and to confirm strong association between neuroticism, extraversion and anxiety.

\section{Fuzzy inference systems}

Fuzzy inference system (FIS) implements human experiences and preferences using membership functions and fuzzy rules. An FIS consists of different processes of fuzzification, creation of knowledge base in form of if-then rules, inferencing and defuzzification. There are two major types of fuzzy system, Mamdani and Sugeno [32]. Sugeno FIS uses the rules of the type "If $x$ is $A_{1}$ and $y$ is $B_{1}$, then $z$ is $f(x, y)^{\prime \prime}$. Since Sugeno FIS does not use output membership function, it needs no defuzzification process. Crisp result is obtained using weighted average of the rules' consequent. Mamdani FIS is the most commonly used fuzzy rule-based model because of its inherent characteristic of handling nonlinear relationship between inputs and output. Another advantage of Mamdani FIS is its expressive power and interpretable rule consequents while loss of interpretability is observed in Sugeno FIS. The block diagram of Mamdani FIS is given in Fig. 2 that involves following components [14].

\subsection{Fuzzification}

This is the process to convert the crisp input to a linguistic variable using the membership function (MF) of the fuzzy sets. Selection of MF depends upon the nature of the problem to be solved using fuzzy rule-based modeling. Gaussian and triangular MFs perform well and better than other types of MFs and are extensively used in fuzzy rule-based models. Zhao and Bose [35] compared the performance of various types of MFs and concluded that triangular MF is superior to any other MF. Triangular MFs are easy to implement and have low computational complexity. Because of aforesaid reasons, we have used triangular MFs in the present study.

\subsection{Fuzzy inference}

Fuzzy inference is the collection of if-then-type rules. Using fuzzy inference, all if-then-type fuzzy rules converts the fuzzy input to the fuzzy output. In the present study min-max method is used for fuzzy reasoning. Figure 3 shows the inference process for the following two rules:

Rule1: If $x$ is $A_{1}$ and $y$ is $B_{1}$, then $z$ is $C_{1}$.

Rule2: If $x$ is $A_{2}$ and $y$ is $B_{2}$, then $z$ is $C_{2}$.

\subsection{Defuzzification}

This converts the fuzzy output of the inference process to crisp using membership functions used in the process of fuzzification. In the present study, we use centroid of area (COA) defuzzification method.

\section{Method}

\subsection{Participants}

In the present study, 22 M.Sc. students of final year (10 males and 12 females) of G. B. Pant University of
Fig. 2 Block diagram for a fuzzy inference system

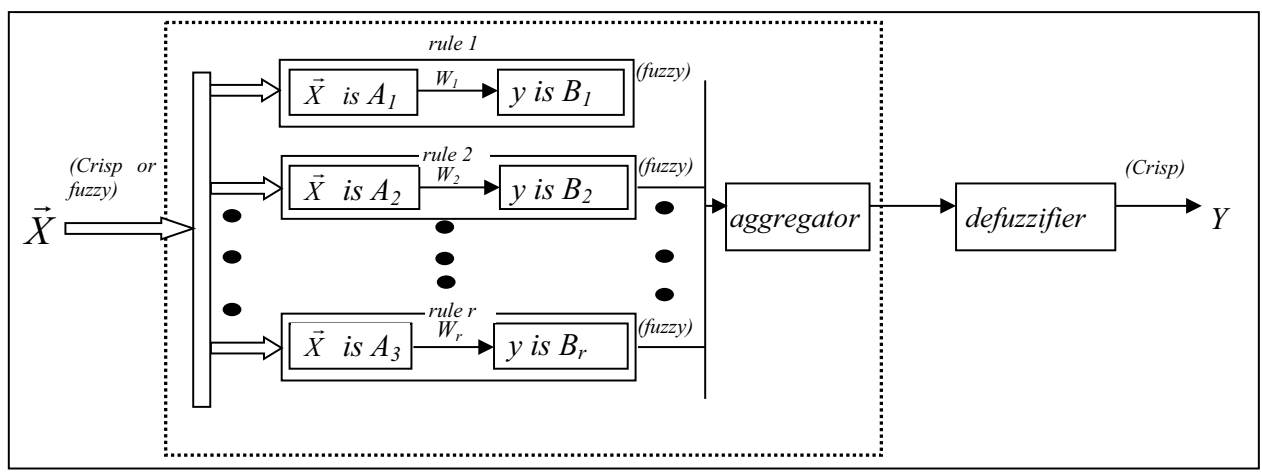

SN Applied Sciences a SPRINGER NatURE journa 
Fig. 3 Inference process in Mamdani FIS [14]

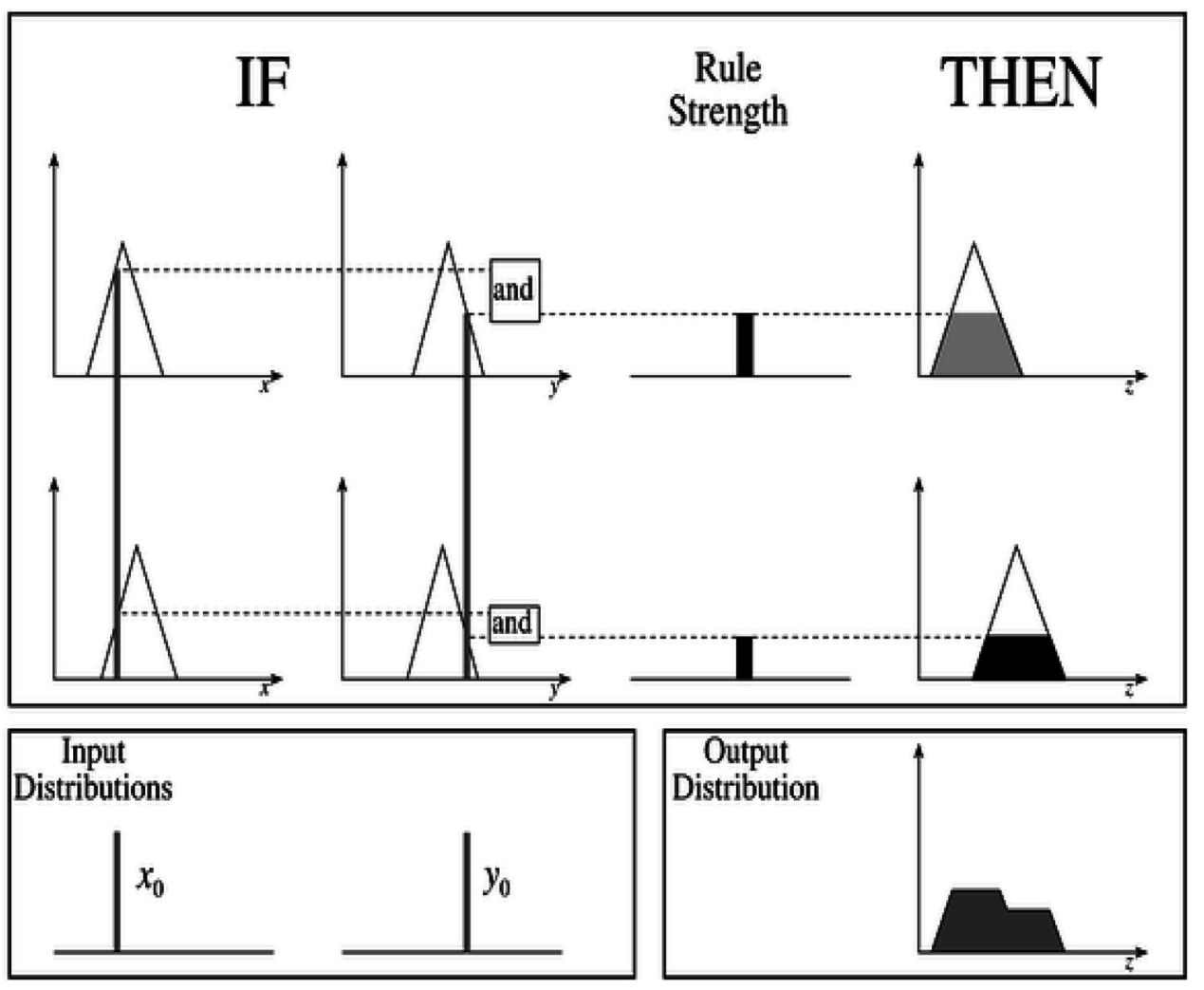

Agriculture and Technology were chosen as the participants. All the participants were from the Department of Mathematics, Statistics and Computer Science.

\subsection{Collection of raw data}

The fully validated databases were created by using Maudsley personality inventory (MPI) and Sinha's comprehensive anxiety test (SCAT). These are the most comprehensive available databases for the information about neuroticism, extraversion and anxiety. In MPI questionnaire, each question was answerable in the form of yes/uncertain/no, whereas in SCAT questionnaire, each question was answerable in form of only yes/no.

\subsection{Model development}

Three Mamdani fuzzy rule-based models are developed. The first two models were single input single output (SISO), and the third model was multi-input single output (MISO).

\subsubsection{Mamdani fuzzy rule-based model for neuroticism}

The first fuzzy rule-based model is developed to convert raw score of neuroticism $(x)$ to standard score of neuroticism $\left(x^{\prime}\right)$. MPI which is considered the most validated database was used to collect raw data for neuroticism. Five triangular membership functions $(A 1-A 5)$ and four triangular membership functions (B1-B4) were used for $x$ and $x^{\prime}$ (Fig. 4) to linguistic representation of raw and standard score of neuroticism with universe of discourse $[0,40]$ and [30-60], respectively.

Table 1 represents the rule base used in model for neuroticism.

\subsubsection{Mamdani fuzzy rule-based model for extroversion}

The second fuzzy rule-based model is developed to convert raw score of extroversion ( $y$ ) to standard score of extroversion $\left(y^{\prime}\right)$. Again MPI questioner was used to collect raw data for extroversion. Five triangular membership functions (C1-C5) and four triangular membership functions (D1-D4) were used for $y$ and $y^{\prime}$ (Fig. 5) to represent raw score and standard score of extroversion linguistically. Universe of discourse for $y$ and $y^{\prime}$ is taken as $[10,40]$ and [30-65], respectively.

Table 2 represents the rule base used in model for extroversion.

Standard scores for both neuroticism and extroversion were obtained by using min-max method for fuzzy inferencing and centroid method for defuzzification. 

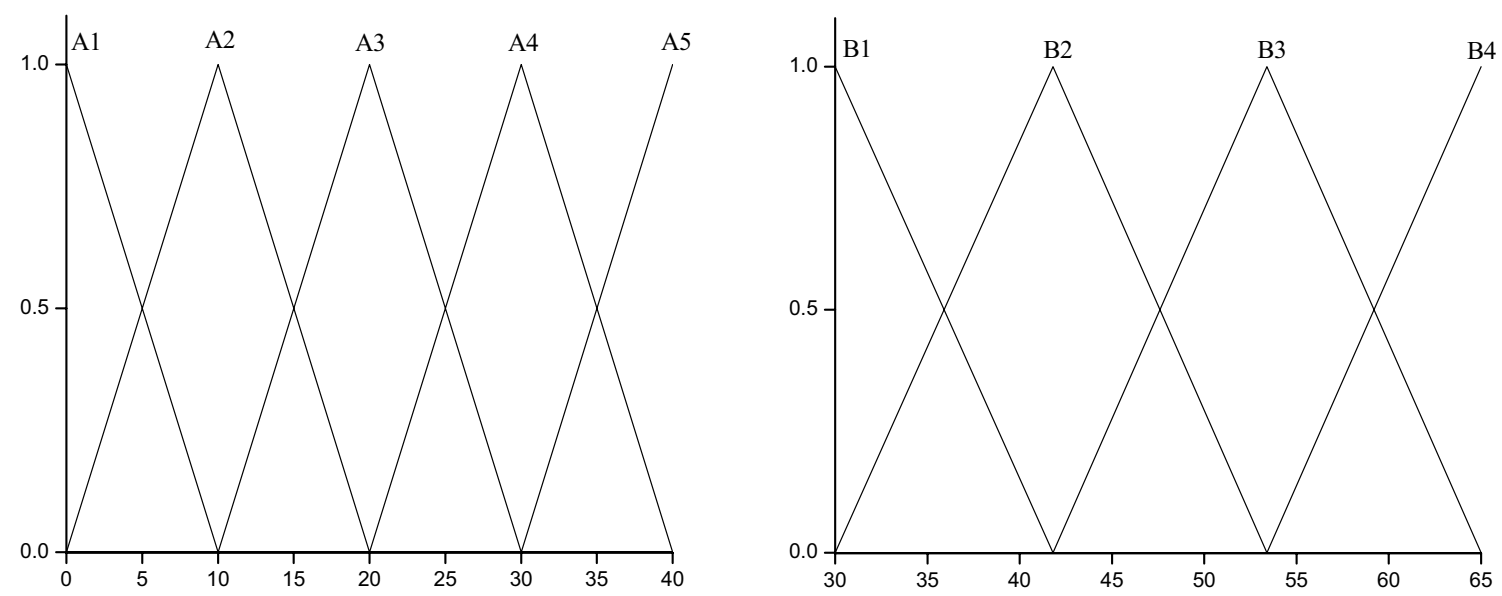

Fig. 4 Fuzzy sets for raw score $(x)$ and standard score $\left(x^{\prime}\right)$ for neuroticism

Table 1 Rule base for neuroticism

Table 2 Rule base for extroversion

\begin{tabular}{lllll}
\hline & B1 & B2 & B3 & B4 \\
\hline A1 & X & X & X & X \\
A2 & X & X & X & X \\
A3 & X & X & X & X \\
A4 & & X & X & X \\
A5 & & & X & X \\
\hline
\end{tabular}

\begin{tabular}{lllll}
\hline & D1 & D2 & D3 & D4 \\
\hline C1 & $\mathrm{X}$ & $\mathrm{X}$ & & \\
$\mathrm{C} 2$ & $\mathrm{X}$ & $\mathrm{X}$ & $\mathrm{X}$ & \\
$\mathrm{C} 3$ & & $\mathrm{X}$ & $\mathrm{X}$ & \\
$\mathrm{C} 4$ & & $\mathrm{X}$ & $\mathrm{X}$ & $\mathrm{X}$ \\
$\mathrm{C} 5$ & & & $\mathrm{X}$ & $\mathrm{X}$ \\
\hline
\end{tabular}

\subsubsection{Mamdani fuzzy rule-based model for anxiety}

The third fuzzy rule-based model is developed to predict the anxiety level of the participants taking standard scores of neuroticism and extroversion from fuzzy models of neuroticism and extroversion (Sects. 3.3.1 and 3.3.2) as input parameters. Observing minimum and maximum value of standard score of both neuroticism and extroversion from Table 3, universe of discourse for both standard scores of neuroticism and extroversion is redefined as $[45,50]$ and $[40,60]$, respectively. Four triangular membership functions (SB1-SB4) and (SD1-SD4) which are shown in Fig. 6a are used for standard scores of neuroticism and extroversion with redefines universe of discourse. This model uses for fuzzy sets (L, M, H, E) for anxiety level with triangular membership functions which are shown in Fig. $6 \mathrm{~b}$ with universe of discourse $[0,60]$.

With the knowledge of experts, the following rule base (Table 4) is constructed for this model to predict anxiety

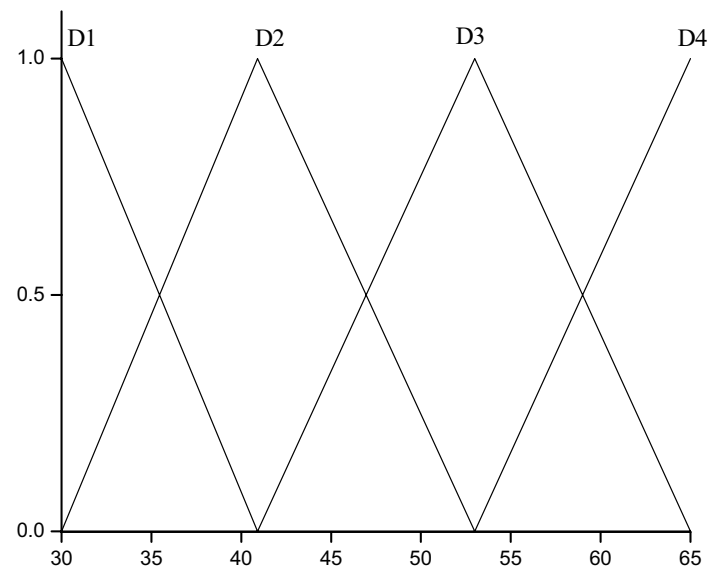

Fig. 5 Fuzzy sets for raw score $(y)$ and standard score $\left(y^{\prime}\right)$ of extroversion 
Table 3 Raw scores and standard scores of neuroticism, extroversion by MPI and fuzzy method

\begin{tabular}{|c|c|c|c|c|c|}
\hline $\begin{array}{l}\text { Raw score of neu- } \\
\text { roticism }\end{array}$ & $\begin{array}{l}\text { MPI scores of } \\
\text { neuroticism }\end{array}$ & $\begin{array}{l}\text { Standard score of neuroticism } \\
\text { by fuzzy method }\end{array}$ & $\begin{array}{l}\text { Raw score of extro- } \\
\text { version }\end{array}$ & $\begin{array}{l}\text { MPI score of extro- } \\
\text { version }\end{array}$ & $\begin{array}{l}\text { Standard score of extro- } \\
\text { version by fuzzy method }\end{array}$ \\
\hline 30 & 57 & 49.563 & 23 & 42 & 42.1182 \\
\hline 10 & 37 & 47.5 & 32 & 57 & 49.3542 \\
\hline 04 & 31 & 47.5 & 16 & 31 & 34.9424 \\
\hline 08 & 35 & 47.5 & 36 & 63 & 49.7085 \\
\hline 15 & 42 & 47.5 & 24 & 44 & 42.3944 \\
\hline 15 & 42 & 47.5 & 22 & 41 & 41.6174 \\
\hline 19 & 46 & 47.5 & 32 & 57 & 49.3542 \\
\hline 10 & 37 & 47.5 & 30 & 53 & 46.2621 \\
\hline 31 & 58 & 49.5333 & 26 & 47 & 42.5906 \\
\hline 29 & 56 & 49.4696 & 30 & 53 & 46.2621 \\
\hline 22 & 59 & 47.5 & 32 & 57 & 49.3542 \\
\hline 27 & 54 & 48.8775 & 22 & 41 & 41.6174 \\
\hline 10 & 37 & 47.5 & 30 & 53 & 46.2621 \\
\hline 07 & 34 & 47.5 & 30 & 53 & 46.2621 \\
\hline 28 & 55 & 49.2461 & 22 & 41 & 41.6174 \\
\hline 34 & 61 & 49.2239 & 25 & 45 & 42.5 \\
\hline 18 & 45 & 47.5 & 32 & 57 & 49.3542 \\
\hline 11 & 38 & 47.5 & 27 & 49 & 42.8552 \\
\hline 24 & 51 & 47.5 & 24 & 44 & 42.3944 \\
\hline 10 & 37 & 47.5 & 24 & 44 & 42.3944 \\
\hline 18 & 45 & 47.5 & 12 & 24 & 32.6194 \\
\hline 36 & 63 & 50.2773 & 24 & 44 & 42.3944 \\
\hline
\end{tabular}

level of the participants taking standard scores of neuroticism and extroversion as inputs.

\section{Performance and statistical analysis}

The performance of any prediction model is measured in terms of error involved in predicted outputs. Less error implies better accuracy in predicted outputs and confirms the goodness of the model. In this study, we have used the following expression for mean absolute percentage error (MAPE) to confirm the better performance of developed models than conventional models of MPI and SCAT.

MAPE $=\frac{1}{n} \sum_{i=1}^{n}\left|\frac{\hat{o}_{i}^{p}-o_{i}^{t}}{o_{i}^{t}}\right| \times 100$

Here, $o_{i}^{t}$ and $o_{i}^{p}$ are the targeted and predicted outputs, respectively. To compare the outputs of developed models with conventional models more rigorously, the standard scores of both neuroticism and extroversion are obtained using fuzzy method as shown in Table 3 and the predicted anxiety of the participants using SCAT and fuzzy method in Tables 5.
Association between actual and predicted level of neuroticism, extraversion and anxiety of the participants is measured using following Pearson's correlation coefficient.

$r=\frac{n\left(\sum x y\right)-\sum x \sum y}{\sqrt{\left[n \sum x^{2}-\left(\sum x\right)^{2}\right]\left[n \sum y^{2}-\left(\sum y\right)^{2}\right]}}$

From Table 6a and b, correlation coefficients $(r=0.96$, $r=0.72),(r=-0.16, r=-0.11)$ and $(r=-0.13, r=-0.09)$ among the scores of neuroticism, extraversion and anxiety confirm stronger association among these parameters than that of conventional methods of MPI and SCAT.

Even though MAPE in prediction of neuroticism using fuzzy method (2.25) is slightly higher than that of MPI method (2.01), less standard deviation in standard scores obtained by fuzzy method (0.96) confirms the out performance of develop model over conventional MPI method. Since both MAPE (0.73) and standard deviation (3.69) are reduced in prediction of extroversion using fuzzy method, it is confirmed that fuzzy method outperforms over conventional method in prediction of extroversion of participants. When standard scores of neuroticism and extroversion using fuzzy method were used in prediction of anxiety of the participants, nominal amount of MAPE 17.64 was observed. The results of paired two-tailed $t$ test are presented in Table 7 . 

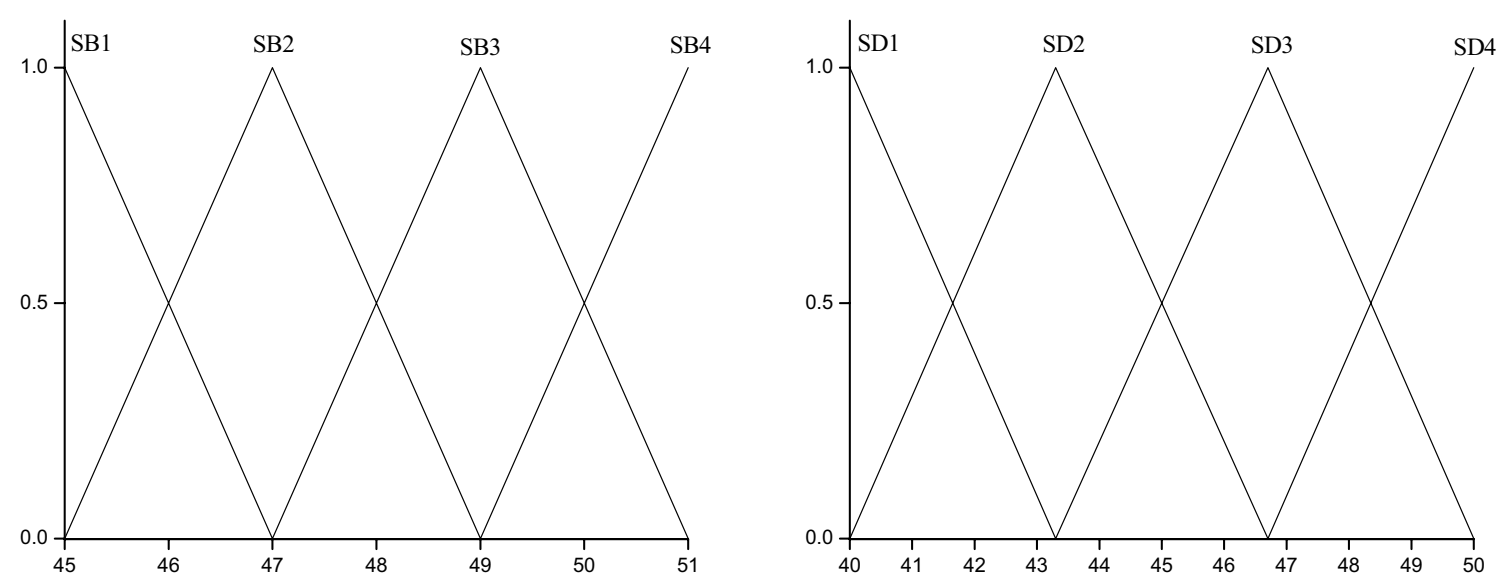

a

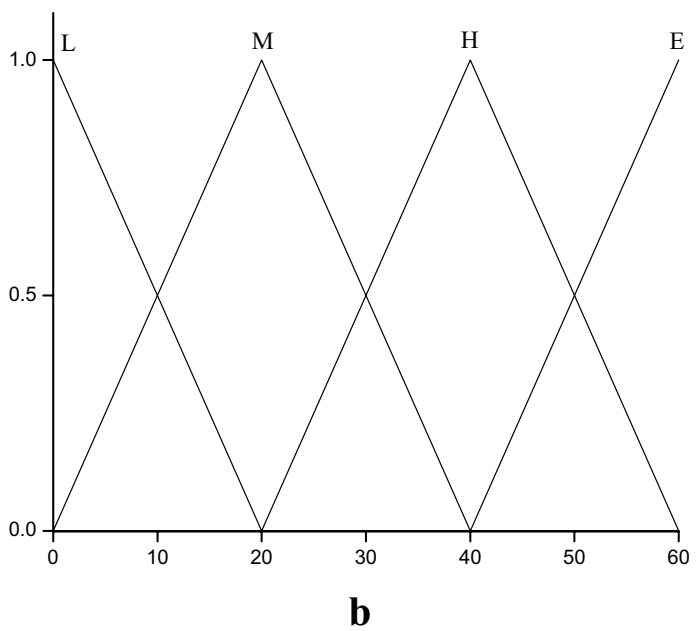

Fig. 6 a Redefined fuzzy sets for standard score of neuroticism, extroversion. b Fuzzy sets for anxiety

Table 4 Rule base for anxiety

\begin{tabular}{|c|c|c|c|c|c|c|c|c|c|c|c|c|c|}
\hline & SD1 & & SD2 & & & SD & & & & SD & & & \\
\hline SB1 & & & & & & $M$ & & & $\mathrm{H}$ & $M$ & & $\mathrm{H}$ & \\
\hline SB2 & L & $M$ & L & $M$ & $\mathrm{H}$ & $\mathrm{L}$ & $M$ & & $\mathrm{H}$ & $\mathrm{L}$ & & $M$ & $\mathrm{H}$ \\
\hline SB3 & L & $M$ & $\mathrm{~L}$ & $\mathrm{H}$ & & $\mathrm{L}$ & $M$ & $\mathrm{H}$ & $E$ & $\mathrm{~L}$ & $M$ & $\mathrm{H}$ & $E$ \\
\hline SB4 & & & $M$ & $\mathrm{H}$ & & $\mathrm{L}$ & $M$ & $\mathrm{H}$ & $E$ & $\mathrm{~L}$ & $M$ & $\mathrm{H}$ & $E$ \\
\hline
\end{tabular}

Even though no significant difference is observed in outputs using conventional and fuzzy methods, proposed models produce more rational results than conventional method. The graph of anxiety of the participants is depicted in Fig. 7.

\section{Conclusion}

The present study proposes Mamdani fuzzy rule-based models to convert raw score of neuroticism and extroversion to their respective standard scores. This study also proposes Mamdani fuzzy rule-based model for prediction of anxiety of the participants using standard scores of neuroticism and extroversion which are obtained from fuzzy methods.

Fuzzy set theory has been proved as an ideal tool to cope the uncertainty, as the participants are sometime biased during answering the psychological questioner or inventory and it leads the imprecision in data. The proposed models are knowledge-driven predictive models that are not very common in psychological research, but can be very useful to overcome subjective indistinctness 
Table 5 Predicted anxiety of the participants using SCAT and fuzzy method

\begin{tabular}{|c|c|c|}
\hline \multirow[t]{2}{*}{ Participant } & \multicolumn{2}{|c|}{ Predicted anxiety } \\
\hline & SCAT method & $\begin{array}{l}\text { Fuzzy } \\
\text { rule-based } \\
\text { method }\end{array}$ \\
\hline S1 & 32 & 30 \\
\hline S2 & 5 & 27.2903 \\
\hline S3 & 18 & 27.531 \\
\hline S4 & 10 & 27.4719 \\
\hline S5 & 15 & 27.2903 \\
\hline S6 & 23 & 27.2903 \\
\hline S7 & 14 & 27.2903 \\
\hline S8 & 13 & 27.2903 \\
\hline S9 & 50 & 30 \\
\hline S10 & 12 & 30 \\
\hline S11 & 22 & 27.2903 \\
\hline S12 & 25 & 30 \\
\hline S13 & 06 & 27.2903 \\
\hline S14 & 10 & 27.2903 \\
\hline S15 & 25 & 30 \\
\hline S16 & 44 & 30 \\
\hline S17 & 36 & 27.2903 \\
\hline S18 & 14 & 27.5162 \\
\hline S19 & 15 & 27.2903 \\
\hline S20 & 02 & 27.2903 \\
\hline S21 & 04 & 26.6993 \\
\hline S22 & 59 & 30 \\
\hline
\end{tabular}

and doubts in psychological research to a certain degree. The major advantage of the develop models is that it enables the use of uncertainty measures to quantify the ambiguity associated with prediction of psychological parameters. Statistical analysis (two-tailed $t$ test and correlation coefficients) also confirms the outperformance of proposed fuzzy rule-based model and their ability to establish stronger relationship among the psychological parameters than conventional methods of MPI and SCAT. The potential use of the presented models includes accurate classification of the participants in extraversion and neuroticism in rapid assessment of their anxiety.

Table 6 Correlation coefficient analysis of scores of neuroticism, extroversion and anxiety obtained using (a) MPI and SCAT methods, (b) fuzzy rule-based models

\begin{tabular}{lrll}
\hline$N=22$ & Neuroticism (MPI) & $\begin{array}{l}\text { Extro- } \\
\text { version } \\
\text { (MPI) }\end{array}$ & Anxiety (SCAT) \\
\hline (a) & & & \\
Neuroticism (MPI) & 1.00 & 1.00 & \\
Extroversion (MPI) & -0.11 & -0.09 & 1.00 \\
Anxiety (SCAT) & 0.72 & & \\
(b) & & & \\
Neuroticism (MPI) & 1.00 & 1.00 & \\
Extroversion (MPI) & -0.16 & -0.13 & 1.00 \\
Anxiety (SCAT) & 0.96 & & \\
\hline
\end{tabular}


Table 7 Paired two-tailed $t$ test analysis

\begin{tabular}{|c|c|c|c|c|c|c|}
\hline \multirow[t]{2}{*}{$N=22$} & \multicolumn{2}{|l|}{ Neuroticism } & \multicolumn{2}{|l|}{ Extroversion } & \multicolumn{2}{|l|}{ Anxiety } \\
\hline & MPI method & Fuzzy method & MPI method & Fuzzy method & SCAT method & Fuzzy method \\
\hline Mean & 46.36 & 48.12 & 47.27 & 44.27 & 20.63 & 28.63 \\
\hline SD & 10.06 & 0.96 & 9.15 & 3.69 & 15.26 & 1.29 \\
\hline MAPE & 2.01 & 2.25 & 0.82 & 0.73 & - & 17.64 \\
\hline$t$ Value & 0.39 & & 0.04 & & 0.023 & \\
\hline
\end{tabular}

Fig. 7 Predicted anxiety of the participants using SCAT and fuzzy method

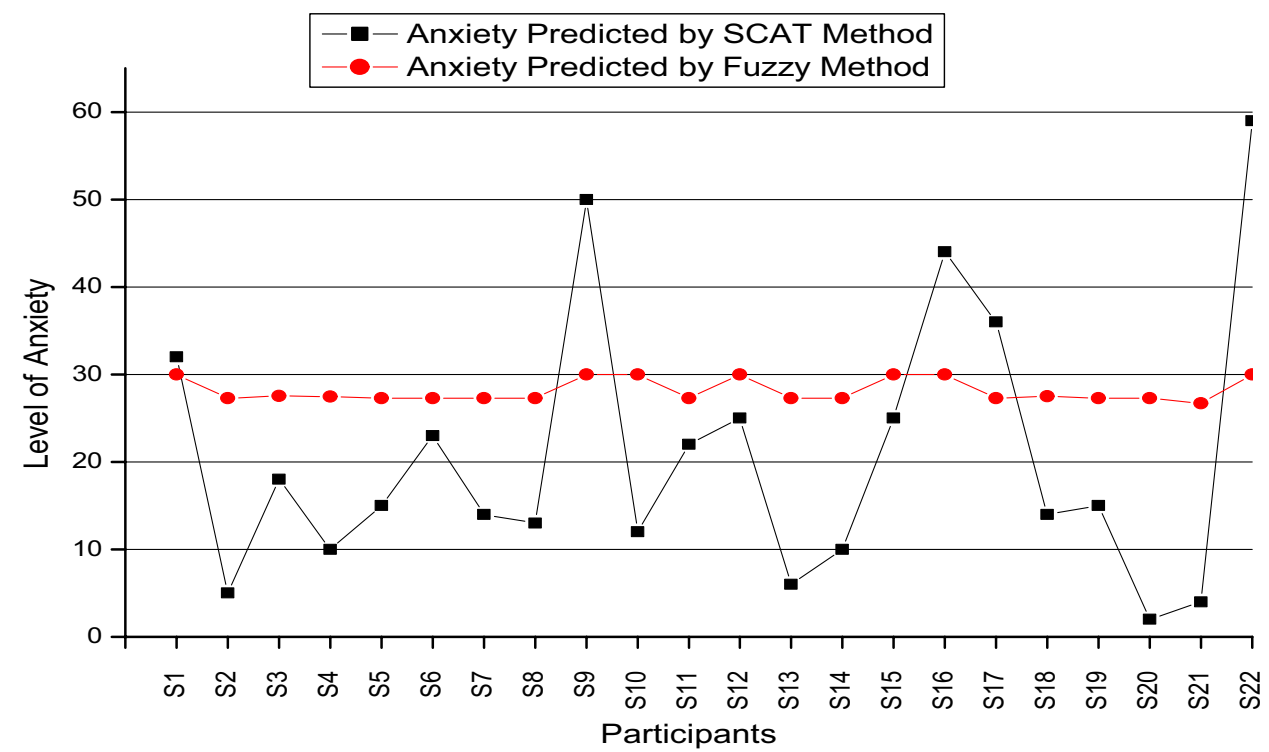

\section{Compliance with ethical standards}

Conflict of interest On behalf of all authors, the corresponding author states that there is no conflict of interest.

\section{References}

1. Averkin AN, Tarasov VB (1987) The fuzzy modeling relation and its application in psychology and artificial intelligence. Fuzzy Sets Syst 22(1-2):3-24

2. Booth T, Murray AL, Marples K, Batey M (2013) What role does neuroticism play in the association between negative job characteristics and anxiety and depression? Pers Individ Differ 55:422-427

3. Chen J-Y (2005) A study on college students anxiety of career decision. J Educ Psychol 28:745-771

4. Costa PT, McCrae RR (1980) Influence of extraversion and neuroticism on subjective well-being: happy and unhappy people. J Pers Soc Psychol 38(4):668-678

5. Devi S, Kumar S, Kushwaha GS (2016) An adaptive neuro fuzzy inference system for prediction of anxiety of students. In: Eighth international conference on advanced computational intelligence (ICACI). Chiang Mai, pp 7-13

6. Egges A, Kshirsagar S, Magnenat-Thalmann N (2003) A model for personality and emotion simulation. In: Palade V, Howlett RJ, Jain L (eds) Knowledge-based intelligent information and engineering systems. KES 2003. Lecture notes in computer science, vol 2773. Springer, Berlin, Heidelberg. https://doi. org/10.1007/978-3-540-45224-9_63

7. Ekong VE, Ekong UO, Uwadiae EE, Abasiubong F, Onibere EA (2013) A fuzzy inference system for predicting depression risk levels. Afr J Math Comput Sci Res 6(10):197-204

8. El-Nasr MS, Yen J, Loerger TR (2000) FLAME-Fuzzy logic Adaptive model of emotions. Auton Agents Multi-agent Syst 3:219-257

9. Eysenck HJ (1959) Maudsley personality inventory. University of London Press, London

10. Ghasem-Aghaee N, Oren TI (2003) Towards fuzzy agents with dynamic personality for human behavior for human behavior simulation. In: Proceedings of the 2003 summer simulation conference. Montreal, $\mathrm{PQ}$, Canada

11. Hesketh T, Pryor R, Hesketh B (1988) An application of a computerized fuzzy graphic rating scale to the psychological measurement of individual differences. Int J Man Mach Stud 29(1):21-35

12. Judge TA, Cable DM (1997) Applicant personality, organizational culture, and organization attraction. Pers Psychol 50:359-394

13. Kushwaha GS, Kumar S (2009) Role of the fuzzy system in psychological research. Eur J Psychol 2:123-134

14. Kwang HL (2005) First course on fuzzy theory and applications. Advances in soft computing. Springer, Berlin

15. Laifa M, Akrouf S, Mammeri R (2018) Forgiveness and trust dynamics on social networks. Adapt Behav 26(2):65-83

16. Martinez-Miranda J, Aldea A (2002) A social agent model to simulate human behavior in teamwork. In: 3rd Workshop on agent-based simulation. Passau, Germany

17. Memmedova K (2017) Fuzzy logic modelling of the impact of using technology on anxiety and aggression levels of students. Procedia Comput Sci 120:495-501 
18. Memmedova K, Quant Q (2017) Quantitative analysis of effect of Pilates exercises on psychological variables and academic achievement using fuzzy logic, quality and quantity. Springer, Basel, pp 1-10

19. Narban DS (2007) Reduction in anxiety of professional college students as a result of placement workshop: an experimental approach. Amity J Behav Forensic Sci 3:234-247

20. Noguchi K, Gohm CL, Dalsky DJ (2006) Cognitive tendencies of focusing on positive and negative information. J Res Pers 40:891-910

21. Price DD, Barrell JE, Barrell JJ (1985) A quantitative-experiential analysis of human emotions. Motiv Emot 9(1):19-38

22. Rauthmann JF (2012) You say the party is dull, I say it is lively: a componential approach to how situations are perceived to disentangle perceiver situation, and perceiver $x$ situation variance. Soc Psychol Pers Sci 3(5):519-528

23. Rousseau $D$ (1996) Personality in computer characters. In: Working notes of the AAAI-96 workshop on Al/A life. AAAI Press, Melno Park, CA

24. Sinha AKP, Sinha LNK (1995) Manual for Sinha's comprehensive anxiety test. National Psychological Corporation Agra, Agra

25. Smithson M (1982) Applications of fuzzy sets concepts to behavioral sciences. J Math Soc Sci 2(3):257-274

26. Smithson M (1988) Fuzzy set theory and the social science: the scope for applications. Fuzzy Sets Syst 26(1):1-21

27. Smithson M, Oden CG (1999) Fuzzy set theory and applications in psychology. In: Zimmermann HJ (ed) Practical applications of fuzzy technologies. Kluwer Academic Publishers, Norwell, pp 557-585
28. Spielberger CD (1972) Anxiety as an emotional state. In: Spielberger CD (ed) Anxiety: current trends in theory and research, vol 1. Academic Press, New York, pp 23-49

29. Srivastava $S$, Pant $M$, Agarwal $N$ (2016) A review on role of fuzzy logic in psychology. In: Pant M, Deep K, Bansal J, Nagar A, Das K (eds) Proceedings of fifth international conference on soft computing for problem solving. Advances in intelligent systems and computing, vol 437. Springer, Singapore

30. Srivastava S, Pant M, Agrawal N (2018) Psychology of adolescents: a fuzzy logic analysis. Int J Syst Assur Eng Manag 9(1):66-81

31. Stoklasa J, Talášek T, Musilová J (2014) Fuzzy approach-a new chapter in the methodology of psychology? Hum Affair 24:189-203

32. Takagi T, Sugeno M (1985) Fuzzy identification of systems and its applications to modeling andcontrol. IEEE Trans Syst Man Cybern 15(1):116-132

33. Zadeh LA (1965) Fuzzy sets. Inf Control 8:338-353

34. Zétényi T (1988) Fuzzy sets in psychology. North-Holland, Amsterdam

35. Zhao J, Bose BK (2002) Evaluation of membership functions for fuzzy logic controlled induction motor drive. In: 28th Annual IEEE conference of the industrial electronics society 2002. Sevilla, Spain

Publisher's Note Springer Nature remains neutral with regard to jurisdictional claims in published maps and institutional affiliations. 